\title{
El doble uso de un camión escolar: representaciones e identificación en la Escuela Regional Campesina de Ayotzinapa (1935-1938)
}

The Uses of a School Bus. Representation and Forms of Identification at the Rural Regional School of Ayotzinapa (1935-1938)

\author{
Karina Araceli Flores Cordero \\ DIE-Cinvestav \\ karinafc05@yahoo.com
}

\begin{abstract}
Resumen
La historia de las Escuelas Normales Regionales, Regionales Campesinas y Normales Rurales ha centrado su atención en explicar las modificaciones de estas instituciones a partir de sus planes de estudio, reformas educativas, formación de estudiantes o movimientos estudiantiles. En este artículo, se buscará demostrar que la cultura material fue otro elemento básico para comprender el funcionamiento diario de estas escuelas. Al analizar el caso de la volcadura de un camión, centraremos nuestra atención en el uso de la tecnología y en las representaciones e identificaciones que éste generó entre la población de alrededor de la Regional Campesina de Ayotzinapa en 1935-1938 y las expectativas entre sus estudiantes.
\end{abstract}

Palabras clave: tecnología, regionales campesinas, Ayotzinapa, camión escolar, viajes de práctica.

\section{Abstract}

The history of secondary and teacher training schools in the Mexican countryside (Regional Normal, Rural Regional and Rural Normal Schools) has focused on curricula, educational reform, student training, and student protest movements. This article sets out to demonstrate that material culture was another important factor in the everyday life of these schools. Through the examination of a school bus accident, it focuses on the uses of technology, and on the representations and forms of identification that this incident provoked amongst the population in the vicinity of the Rural 
Regional School of Ayotzinapa, as well as the expectations it generated amongst students between 1935 and 1938.

Keywords: technology, Rural Regional Schools, Ayotzinapa, school bus, school trips.

\section{Introducción}

Para lograr la pacificación del país después del periodo de la Revolución mexicana fue necesario implementar un proyecto de nación que incluyera uno educativo "para disciplinar y canalizar las energías de los campesinos rebeldes" (Vaughan, 2000: 13), de tal forma que, la creación de escuelas rurales federales y la formación de un nuevo tipo de maestro para estos planteles sirvieron en la construcción de una identidad nacional y la modernización del campo.

Dentro de este proyecto modernizador, el campesino, a quien se le asociaba con situaciones de atraso y superstición, fue el destinatario de la política educativa; de tal modo que el campesinado se convirtió en un nuevo sector social capaz de incrementar la productividad agrícola y de conformar una cultura nacional, formó parte del discurso educativo desde los años 30 (Palacios, 1996 y 1999).

La estabilidad política interna fue asunto prioritario para la política del general Álvaro Obregón; mientras que para Plutarco Elías Calles, el mejoramiento económico fue el eje principal de su gobierno, el cual, se lograría a través de "la reducción al mínimo de la injerencia del extranjero en la vida nacional y la explotación intensiva de la riqueza de México..." (Torres Hernández, 1998: 191). La creación de las Escuelas Centrales Agrícolas, planteles destinados para el campo con la finalidad de acrecentar su producción y capacitar a técnicos agrícolas, fue parte de la tan anhelada modernización. Si bien la educación para las zonas rurales estuvo pensada como algo específico, como bien ha señalado Marco Calderón Mólgora (2013), los valores que se buscaron establecer tomaron como punto de referencia la civilización de una vida urbana.

En 1932, las Escuelas Centrales Agrícolas dieron paso a la formación de las Escuelas Regionales Campesinas, encargadas de fusionar las tres instituciones de educación rural: Misiones Culturales, Centrales Agrícolas y Normales Rurales. Dos años para formar técnicos agrícolas y dos años más para formar maestros rurales fue el periodo que comprendía el plan de estudios de la Regional, los alumnos de entre 12 y 26 años (Civera, 1997) debían presentar una constancia elaborada por un comisario ejidal donde acreditaran su procedencia 
campesina para ingresar. El estudiante recibiría una formación acorde a su contexto que le permitiera hacer efectiva la labor con las comunidades. ${ }^{1}$

En este sentido, el trabajo con las poblaciones cercanas, herencia de las primeras Casas del Pueblo en donde escuela y comunidad eran una, se extendió aún más durante la educación socialista en 1934. La formación de los alumnos en las Regionales propició que éstos se convirtieran en líderes agrarios que pugnaran por la liberación campesina y que por medio del cooperativismo abandonaran el fuerte sentido individualista y trabajaran en colectivo, consiguiendo una sociedad sin clases (Civera, 2004).

La educación práctica ${ }^{2}$ no sólo sirvió como método pedagógico al interior de este tipo de planteles, sino que también ayudó a resolver algunas carencias materiales. Como Alicia Civera señala, en las prácticas de los estudiantes con las comunidades "la organización de fiestas y festivales integraba la confección de ropa, la escritura de poemas y obras de teatro, la educación cívica y la historia, la realización de bailes de todo México, la interpretación de canciones populares e himnos agraristas y la realización de tablas gimnásticas" (Civera, 2004: 7), así, los alumnos cubrían, en parte, la escasez de útiles y materiales escolares y lograban acercarse a las poblaciones para ganarse con ello su confianza.

En este sentido, el aprovechamiento de los recursos materiales dentro de las Escuelas Regionales Campesinas fue una constante. El 12 de octubre de 1935, en las inmediaciones de la escuela de Ayotzinapa aconteció un accidente escolar. El camión que transportaba a estudiantes y maestros de la Regional al poblado de Tixtla con motivo del festejo del Día de la Raza se volcó a un kilómetro de distancia del plantel, en este accidente pereció una estudiante y hubo varios heridos. Unos meses antes del accidente, el director, Rubén Castillo Penado, enfrentó diversos cuestionamientos por parte del Departamento de Tráfico del estado por el mal uso del camión que contenía carrocería de carga y aun así servía para transportar alumnos. Cuando el percance ocurrió, las autoridades escolares fueron duramente criticadas por organizaciones de estudiantes y campesinos que argumentaron que se trató de un total descuido de la seguridad de sus hijos y vecinos. De tal forma que, en 1936 y después del emplazamiento a huelga por parte de los alumnos, las autoridades educativas otorgaron un nuevo transporte escolar para dirimir el conflicto.

${ }^{1}$ En 1930, las Escuelas Regionales Campesinas retomaron el interés por la educación técnica heredada del siglo XIX y a las materias que antes se impartían en las normales rurales se les agregaron clases de industrias rurales, ganadería, agricultura y oficios (Civera, 2004). La enseñanza retomada del contexto inmediato a las escuelas dejó un margen de independencia para que cada plantel tuviera su propio plan de estudios. Sin embargo, como Alicia Civera señala, para dichos años la educación práctica y el cooperativismo fueron puntos centrales que aglutinaron las distintas prácticas de las diferentes Regionales (Civera, 2004).

2 Durante la década de los años veinte, el conocimiento memorístico y erudito basado en los libros fue duramente cuestionado por pedagogos como Moisés Sáenz, Rafael Ramírez y Enrique Corona, de tal forma que las escuelas rurales y, entre ellas, las normales regionales, hicieron de la escuela de la acción y la enseñanza práctica, entendida como un conocimiento útil y retomado de ejemplos de la vida, su método pedagógico. 
Como sugiere Robert Darnton (1987), un episodio significativo puede ayudarnos a comprender los diversos significados de una cultura en particular. El accidente del camión escolar que a continuación presento es un ejemplo dentro de la historia de Ayotzinapa que resulta relevante porque me permitió adentrarme en la cultura escolar y distinguir el óptimo aprovechamiento de los recursos disponibles como medio para resolver la escasez material. A través del análisis de un particular acontecimiento se puede observar cómo el doble uso de un camión afectó las relaciones con las comunidades más cercanas y, a su vez, generó nuevas expectativas entre la población estudiantil.

Los estudios sobre historia de la tecnología han puesto sobre la mesa de discusión los valores, la ideología, los discursos, los conocimientos de uso, etc. de lo objetos o artefactos que emplea y consume una determinada sociedad (Tinajero y Freeman, 2013; Lawn y Grosvenor, 2005), reflexión muy pertinente también para el caso del salón de clases ya que "for historians, the problem appears to be that the object is viewed without context and so the discourse no longer activates or sorround it. A desk is a desk, not a device for managing effective pupil behaviour and learning" (Lawn y Grosvenor, 2005: 8). No obstante, los estudios sobre cultura material en las escuelas se han volcado sobre algunos artefactos clásicos de uso escolar, tales como los uniformes, el edificio, los libros, la arquitectura escolar, los útiles y los manuales. ${ }^{3}$ Si bien el presente trabajo propone estudiar un objeto en particular y de los discursos que se generaron alrededor de éste, es importante adentrarnos en el contexto de los planteles campesinos durante los años 30 para entender por qué un camión de carga fue trascendental para la vida de estas escuelas.

¿Qué tipo de tecnologías se usan y perduran en un plantel de educación superior para campesinos? ¿Cuáles son los discursos y situaciones que posibilitó su uso? El accidente del camión escolar de la Escuela Regional Campesina de Ayotzinapa del 12 de octubre de 1935 nos remite a imaginar cómo eran los camiones escolares en este tipo de planteles y nos proporciona respuestas sobre la importancia de un artefacto en la construcción de legitimidad frente a la población. El objetivo de este artículo es indagar en el uso que se le dio a la

${ }^{3}$ La compilación hecha por Martin Lawn e lan Grosvenor que reúne un número considerable de objetos y discursos en torno a la cultura material de las escuelas, es quizá una de las obras más importantes para entender la forma en la que los artefactos se relacionan con el control y la disciplina en el aula. En dicha obra se analizan objetos como los uniformes escolares, las construcciones de las escuelas, los útiles, los muebles, etcétera. Para el caso de la historiografía sobre cultura material en español, buena parte de los estudios han centrado su atención en diversas fuentes producto de la materialidad de las escuelas, tales como libros, imágenes o arquitectura escolar. Capítulos de libros como los de Claudia Garay Molina (2010) para el caso mexicano, o el de Nicolás Arata (2014) y Patricia Barbieri (2014), para el caso argentino, dan cuenta de la producción de imágenes, espacios y arquitectura escolar como parte de la formación de representaciones a través de los libros de texto, de la promoción de la lectura a partir del diseño de espacios o de la valoración de la estética escolar y la consiguiente formación de identidades. Para México, Carlos Ortega propone analizar la arquitectura escolar desde el vínculo entre historia política de la tecnología y arquitectura través del estudio de manuales escolares (Ortega y Saldaña, 2013). 
tecnología escolar —un camión-, el tipo de situaciones que posibilitó entre la población de alrededor, y las representaciones e identificaciones generadas a partir de la posesión del vehículo, narrado a través de un acontecimiento.

\section{El accidente del autobús escolar en Tixtla}

El proyecto de carreteras nacionales se inició de manera oficial en 1925 con la Comisión de Caminos y la construcción de cuatro secciones principales: "Ciudad de México a Cuernavaca (en el camino de Acapulco), Puebla (camino a Veracruz) y Pachuca (camino a Nuevo Laredo), así como Norte de la ciudad industrial de Monterrey a Nuevo Laredo (también en la ruta México-Nuevo Laredo)" (Waters, 2006: 223).

El 11 de noviembre de 1927 se inauguró la carretera México-Acapulco con 485 kilómetros del Palacio Nacional a la plaza principal de Acapulco. Para el historiador, Tomás Bustamante Álvarez, tres motivos propiciaron que el general Obregón construyera la carretera: un saldo de cuentas a favor de los guerrerenses por el apoyo que prestaron a su campaña presidencial, lo incomunicado del puerto a pesar de ser un punto estratégico pero, sobre todo, la movilización del líder agrarista, Juan R. Escudero, en Acapulco que desde 1920 impulsó la construcción de una carretera hacia la Ciudad de México (Bustamante, 1998; Jacobs, 1990). La carretera México-Acapulco comunicó las principales ciudades del estado de Guerrero con el centro del país y conectó las distintas regiones del estado: Tierra Caliente, Costa Grande, Costa Chica, Montaña y Chilapa-Tlapa (Bustamante, 1987). ${ }^{4}$ Desde la conformación de la Comisión Nacional de Caminos (después Dirección Nacional de Caminos, 1932) el esfuerzo por legislar el uso y la construcción de carreteras sirvió al fin político de reclamar el territorio del estado nacional (Fulwider, 2009: 38). Por su parte, la participación de los gobiernos estatales en la administración de los caminos se manifestó a través de las Juntas Locales de Carreteras.

A partir de la construcción de la vía México-Acapulco, otras siguieron su ejemplo y comenzaron a trazarse desde el entroncamiento con la carretera nacional. Éste fue el caso de las vías Tixtla-Chilpancingo, Chilapa-Tixtla, Petaquillas-Tepechicotlán y MochitlánQuechultenango, iniciadas desde 1925 (Benítez, 1928; Bustamante, 1998). El tránsito de vehículos para finales de 1935 no debió ser algo común, pues como veremos con el caso de la volcadura del camión escolar que trasladaba a varias alumnas de la Regional a la ciudad

\footnotetext{
${ }^{4}$ La importancia de la construcción de la carretera México-Acapulco posibilitó otro tipo de servicios como la comunicación postal y un sistema de transportes, para 1936 comenzó a funcionar la primera línea de autobuses Flecha Roja y en 1937, la primera línea de autobuses con destino Chilpancingo-Chilapa. Para 1938, las oficinas postales en el estado fueron 95; previo a éstas, ya existía el telégrafo en las principales ciudades del estado.
} 
de Tixtla, el conductor al parecer no tenía suficiente experiencia en el manejo de los camiones proporcionados por la Secretaría de Educación Pública (SEP). Si bien no se puede atribuir el accidente a este único factor, fue significativo, por ser el chofer del camión, maestro de Taller, Gilberto Martínez, el único consignado como responsable. ${ }^{5}$

Como parte del material solicitado a la SEP el 5 de abril de 1935 por el director de la Escuela Regional de Ayotzinapa, Rubén Castillo Penado, a nombre de la Sociedad de Alumnos y Maestros del plantel, se pidió el préstamo de dos camiones de la Secretaría con el fin de realizar excursiones de labor social durante 10 días en el puerto de Acapulco, pero el Departamento argumentó que no disponía de unidades destinadas a tal comisión. Sin embargo, cinco meses después, el director Penado reportó en una carta enviada al gobernador ciertos problemas con el Departamento de Tráfico del estado por motivo del camión "marca 'Reo' con que últimamente le ha sido dotada por la Secretaría de Educación Pública, de donde depende esta Escuela". ${ }^{6}$ La carta del director refería los cuestionamientos que el Departamento de Tráfico hizo sobre el libre tránsito del camión, por lo que solicitaba su intervención para otorgar "las facilidades a que tiene derecho" la institución. La inconformidad de la dependencia del estado se debía a dos motivos: el primero, que el camión era de carga, no de pasajeros, y aun así transportaba grupos de alumnos de la Regional.

En palabras del director, los estudiantes viajaban a Tixtla "para diferentes trabajos de acción social y otras veces han ido a ésa para ayudar a cargar los materiales de construcción que estamos comprando con el citado camión"? Por su parte, el jefe de Tráfico señalaba que por contar el camión con carrocería de carga, sólo podía ser usado para tales fines y que por lo tanto "no permitirá que vaya lleno de "pasajeros" o "macheteros", como llama a nuestros alumnos; no obstante que nuestro camión tiene en las dos portezuelas un grande Escudo Nacional con un letrero que dice: 'Secretaría de Educación Pública-Escuela Regional Campesina. Ayotzinapa, Gro'”. ${ }^{8}$ Castillo Penado defendió el doble uso, como camión de carga y autobús escolar, enfatizando que en los viajes únicamente habían participado alumnos y personal del plantel y que el material de construcción era para uso del mismo.

${ }^{5}$ En 1937 se organizó la primera cooperativa de autobuses Chilpancingo-Chilapa (Bustamante, 1987). Para 1935 el total de camiones registrados en el país era de 23,792, de los cuales 10,523 eran parte del sector público (Fulwider, 2009).

${ }^{6}$ AGN, SEP, DEANR, Sección Guerrero, Caja 33281, Referencia x/143(x-5)(727.1)/-1, exp. s/n, leg. s/n, foja 3, Carta del director, Rubén Castillo Penado al C. Gobernador Constitucional de Estado, Ayotzinapa, Gro., 11 de septiembre de 1935.

${ }^{7}$ AGN, SEP, DEANR, Sección Guerrero, Caja 33281, Referencia x/143(x-5)(727.1)/-1, exp. s/n, leg. s/n, foja 3, Carta del director, Rubén Castillo Penado al C. Gobernador Constitucional de Estado, Ayotzinapa, Gro., 11 de septiembre de 1935.

${ }^{8}$ AGN, SEP, DEANR, Sección Guerrero, Caja 33281, Referencia x/143(x-5)(727.1)/-1, exp. s/n, leg. s/n, foja 3, Carta del director, Rubén Castillo Penado al C. Gobernador Constitucional de Estado, Ayotzinapa, Gro., 11 de septiembre de 1935. 
El segundo motivo por el cual el empleado estatal no dejaba circular libremente el camión era que llevaba placas del Distrito Federal que debían ser reemplazadas por unas del estado de Guerrero; el tiempo fijado para realizar dicho cambio era de un mes, y si bien Penado no se oponía a dicha permuta, alegaba no haber hecho tal tránsito por estar dentro del plazo en el que las placas del Distrito todavía estaban vigentes. Así, se mostró molesto por los constantes cuestionamientos a los que era sujeto:

En la inmediata Ciudad de Tixtla, ya se nos pregunta por el Agente de Tráfico en dicha Ciudad, si nuestro camión tiene su boleta de la última revista, si están buenos sus frenos, luces, etc.; en todo lo cual nosotros seríamos los primeros en procurar que estuvieran en buen estado; pero nos sorprende que se pare el camión para estas preguntas cuando ningún automóvil de la Ciudad de Tixtla, al cual no se le exigen estos requisitos como a nosotros, en forma tan apremiante, se encuentra como nuestro camión "Reo" que es completamente nuevo. ${ }^{9}$

De esta forma, solicitaba las facilidades del gobernador para el libre manejo del camión y aprovechar todos los usos que pudiera darle la institución.

El 26 de septiembre, Penado escribió por última vez sobre el conflicto con el agente de Tráfico y solicitó ante el Departamento de Enseñanza Agrícola y Normal Rural (DEANR) la intervención del secretario general del estado para que le otorgara facilidades y así cumplir con lo dispuesto por el Reglamento de Tránsito. Concluía "[...] manifestando que nuestro Jefe de Taller, C. Gilberto Martínez ya sacó su licencia de chofer en el Estado, y en vista de que cada día ha mejorado sus conocimientos en el manejo del camión, dicho empleado ya se ha hecho cargo totalmente de él, y lo ha llevado hasta la Ciudad de Iguala, sin ningún contratiempo y perfectamente bien". ${ }^{10}$ Wendy Waters destaca la importancia de los caminos para la conformación de nuevos deseos y gustos de la población. Nuevas áreas de trabajo como chofer de autobuses o reparador de vehículos fueron empleos atractivos para los hombres que abandonaron el trabajo agrícola (Waters, 2006; Tinajero y Freeman, 2013).

La noche del suceso fue descrita por el director, Rubén Castillo Penado, en una misiva enviada al jefe del Departamento de Enseñanza Agrícola del 14 de octubre de 1935. Según sus palabras, el día 12, con motivo del festejo del Día de la Raza, los alumnos de la Escuela Regional celebrarían con escolares de la ciudad de Tixtla una velada. Durante el transcurso del día, alrededor de 100 estudiantes asistieron a un encuentro de basquetbol con el $7^{\circ}$

\footnotetext{
${ }_{9}^{9}$ AGN, SEP, DEANR, Sección Guerrero, Caja 33281, Referencia x/143(x-5)(727.1)/-1, exp. s/n, leg. s/n, foja 3, Carta del director, Rubén Castillo Penado al C. Gobernador Constitucional de Estado, Ayotzinapa, Gro., 11 de septiembre de 1935.

${ }^{10}$ AGN, SEP, DEANR, Sección Guerrero, Caja 33281, Referencia x/143(x-5)(727.1)/-1, exp. s/n, leg. s/n, foja 6 , Carta del director, Rubén Castillo Penado al Jefe del DEANR, Ayotzinapa, Gro., 26 de septiembre de 1935.
} 
Batallón en la Ciudad de Bravos, la mayoría de éstos, se transportó a esa población en dos viajes que el camión tuvo que realizar por ser éstos demasiados. Mientras algunos estudiantes regresaban del encuentro deportivo caminando - motivo por el cual se retrasó la cena en el plantel一, el director advirtió que únicamente podrían abordar al camión "las señoritas que estuvieran listas para concurrir al festival, correspondiendo a los alumnos ir a pie".1.

Alrededor de las 8:30 de la noche, el camión salió de la escuela de Ayotzinapa rumbo a Tixtla con aproximadamente 43 estudiantes y tres o cuatro hombres (maestros y alumnos). Después de recorrer un kilómetro y antes de llegar a la calzada llamada "Calle Ancha", al salir de la última curva e intentar librar una puerta de tranca, el transporte se volcó "arrojando a sus ocupantes contra el alambrado que limita la carretera en el punto indicado". 12 En el accidente, perdió la vida la alumna del primer año de Normal, Alicia Aburto, y treinta y siete más quedaron lesionados. Los motivos a los cuales el director atribuyó el percance fueron "difíciles de precisar", pero continuaba: "posiblemente por exceso de velocidad y el propósito de salvar la tranca, viró de dirección y fue a estrellarse sobre el borde del camino y un canal de agua en el lado izquierdo del mismo...". 13

El personal, los estudiantes, así como del médico de la escuela y personas que ejercían la medicina en Tixtla acudieron al lugar para trasladar a los heridos y proporcionarles los primeros auxilios en el plantel. Por su parte, el director de Ayotzinapa Castillo Penado, se trasladó a Ciudad de Bravos para dar cuenta de lo ocurrido al director de Educación Federal quien gracias a sus gestiones logró que se enviaran tres médicos de esa capital con medicamentos y materiales quirúrgicos necesarios. ${ }^{14}$

El jefe del Departamento de Enseñanza Agrícola, Luis Villarreal, relató en su carta al subsecretario de Educación del 14 de octubre de 1935, los acontecimientos y destacó la rápida actuación del personal escolar que se movilizó por la atención de los heridos, gracias a lo cual, sólo se lamentó la muerte de una alumna: "Es justo reconocer que todas las dependencias del Cobierno Federal y la Cruz Roja, a quienes se les solicitó alguna ayuda, respondieron con entusiasmo y rapidez" ${ }^{15}$ El 13 de octubre, la ambulancia de la Cruz Roja trasladó de Ayotzinapa a la Ciudad de México a las alumnas Emilia Díaz y Esperanza Ortíz, mientras que otra ambulancia trasladó al siguiente día a Godoleva Salgado, Aldegunda González,

\footnotetext{
${ }^{11}$ AGN, SEP, DEANR, Sección Guerrero, Caja 33275, Referencia X/402(x-5)(727)/-1, exp. s/n, leg. s/n, foja 21, Carta del director Rubén Castillo Penado al Jefe del DEANR, Ayotzinapa, Gro., 14 de octubre de 1935.

12 AGN, SEP, DEANR, Sección Guerrero, Caja 33275, Referencia X/402(x-5)(727)/-1, exp. s/n, leg. s/n, foja 21, Carta del director Rubén Castillo Penado al Jefe del DEANR, Ayotzinapa, Gro., 14 de octubre de 1935.

${ }^{13}$ AGN, SEP, DEANR, Sección Guerrero, Caja 33275, Referencia X/402(x-5)(727)/-1, exp. s/n, leg. s/n, foja 21, Carta del director Rubén Castillo Penado al Jefe del DEANR, Ayotzinapa, Gro., 14 de octubre de 1935.

${ }^{14}$ La distancia entre la ciudad de Chilpancingo de Bravos, capital del estado, y Tixtla era aproximadamente de 15 kilómetros al este de la capital (INEGI, 1998: 1).

${ }^{15}$ AGN, SEP, DEANR, Sección Guerrero, Caja 33275, Referencia X/402(x-5)(727)/-1, exp. s/n, leg. s/n, foja 3, Carta del Jefe del DEANR al C. Subsecretario de Educación Pública, México, D.F., 14 de octubre de 1935.
} 
Rufina Santos, Joaquina León, Esteban Guerrero y al profesor Germán Nava. Todavía en 1939 el servicio hospitalario era insuficiente en Guerrero, pues existían pocos centros de salubridad. Con un presupuesto anual de 174,000 pesos a cargo de la federación y del estado se establecieron centros de higiene en Chilpancingo, Coyuca de Catalán, Chilapa, Iguala, Ometepec, Olinalá, Petatlán, Taxco, Teloloapan, Tlapa, Tecpan y Tixtla. El hospital de Guerrero de Chilpancingo abrió sus puertas en 1942, después de la reconstrucción de su edificio (Peña de la, 1949).

El 15 de octubre de 1935, uno de los maestros que estuvo en el camión durante el accidente, Lorenzo M. Castorela, se encontraba en la Ciudad de México acompañando a los estudiantes heridos. Mediante una carta al jefe del DEANR informó sobre los acontecimientos del día 12

\begin{abstract}
desgraciadamente no fue posible obtener comunicación con la ciudad de México, tal como lo deseaba, para comunicar a la Secretaría los sucesos que acababan de desarrollarse, por más que el Jefe de la Oficina de Correos y Telégrafos estuvo llamando. Este intento de comunicarse con la capital, se hizo como a eso de las 21 horas 30 minutos, hora en que las oficinas de las pequeñas poblaciones tienen cerradas sus puertas. $^{16}$
\end{abstract}

Además de relatar la actuación del personal, la correspondencia destacó varios detalles significativos como los pormenores de la vida escolar, la competencia de los alumnos en un partido de basquetbol con la quinta del regimiento de Chilpancingo con motivo del festejo del Día de la Raza, que los alumnos regresaron a tomar su cena a la regional campesina y que después de eso se prepararon para asistir a un festival musical en el teatro "Armendáriz" de la primaria de Tixtla "Ignacio Manuel Altamirano"; así como el júbilo con el que las señoritas de la Regional festejaron un incidente en el camión, antes de tener lugar el accidente.

\title{
Comunidad escolar: la demanda de un transporte y la formación de vínculos con otros estudiantes campesinos
}

En las discusiones que se suscitaron durante los Congresos de Instrucción Pública (18891890, 1890-1891) se acordó adoptar el método objetivo en el proceso de aprendizaje de las asignaturas (Martínez, 2002: 284), como parte de dichas discusiones, la Ley de Instrucción

${ }^{16}$ AGN, SEP, DEANR, Sección Guerrero, Caja 33275, Referencia X/402(x-5)(727)/-1, exp. s/n, leg. s/n, foja 11 , Carta del profesor de materias Normales, Lorenzo M. Castorela al Jefe del DEANR, Luis Villarreal, México, D.F., 15 de octubre de 1935. 
Pública de 1890 integró la materia Lecciones de cosas, consistente en observar los objetos materiales para saber de qué estaban hechos y su utilidad. El libro era un auxiliar en la adquisición del conocimiento de los objetos que cuando no podían ser ejemplificados de manera presencial, servía para mostrar sus ilustraciones. Las excursiones escolares fueron un medio más para reforzar los conocimientos prácticos de los alumnos y promover el amor a la naturaleza. Para 1904, las excursiones se generalizaron (Martínez, 2002: 288), entre los alumnos beneficiados con este tipo de viajes se encontraban los normalistas que, de acuerdo con Lucía Martínez, en sus viajes de práctica se transportaron en ferrocarril para conocer el valle de México. Estos viajes no debieron ser muy comunes para este periodo, pues la autora concluye su artículo explicando lo costoso que resultaban este tipo de prácticas, por lo que "[...] los viajeros que participaron en estos paseos escolares fueron alumnos privilegiados por tener acceso al conocimiento y a la experiencia, un privilegio que no solo tiene que ver con lo pedagógico sino también con lo económico [...]" (Martínez, 2002: 297).

Los costos que un viaje escolar representaba debieron significar una limitante para este tipo de prácticas ya que era elevado el precio de un viaje por ferrocarril, que para 1904 era el medio de transporte más difundido. ${ }^{17}$ Los 19,000 kilómetros de líneas de tren que había en 1910 hicieron del sistema ferroviario mexicano el segundo más importante en América Latina, solo después del de Argentina (Guajardo y Riguzzi, 2013). En 1930, cuando Frank Tannenbaum estudió 3611 poblados rurales de México que contenían 17\% por ciento de la población total, evidenció que 93.1\% de las ciudades no tenían acceso al ferrocarril (Guajardo y Riguzzi, 2013).

El 31 de octubre y el 6 de noviembre de 1932, alumnos de la escuela Normal Rural de Oaxtepec, Morelos realizaron una excursión en el estado que les permitió movilizar a 71 estudiantes en dos camiones con cuatro viajes a la estación de ferrocarril (Martínez, 2009: 3), cumpliendo con los objetivos de recorrer "[...] lugares históricos, observar detalles geográficos y geológicos de la zona, conocieran las costumbres de los poblados, las condiciones en que se encontraban las escuelas y establecieran contacto con profesores de otras entidades como Puebla y el Estado de México" (Martínez, 2009: 8). Aunque no sabemos qué tan frecuentes eran estas excursiones escolares, el uso de tecnologías automotrices y carreteras parece haber sido importante en su difusión y demanda.

De 1925 a 1940, el gobierno mexicano junto con sus connacionales construyó más de 10,000 kilómetros de caminos, situación que no sólo posibilitó el intercambio comercial al

\footnotetext{
17 "Si consideramos que, hacia 1910, un boleto en primera clase resultaba tres veces más caro que uno en diligencia o el costo de un viaje promedio de $67 \mathrm{~km}$ en segunda clase era de $\$ 1.63$ equivalente a 9.4 días de salario mínimo en la agricultura y dos días de trabajo para los grupos mejor remunerados como los burócratas, comprenderemos que se evitaba viajar en ferrocarril, excepto en casos en que las largas distancias hicieran poco práctico o peligroso el viaje por otro medio" (Martínez, 2002: 297).
} 
comunicar distintas regiones, sino que también fomentó el nacionalismo. Como ha señalado Wendy Waters "Nationalism results from numerous people constructing in their own minds a vision of their country and believing in that fiction. Roads helped Mexicans to know their country better (even if they did not travel themselves), supporting the development of nationalism" (Waters, 1999: 24).

Además, los viajes de práctica escolares propiciaron también una comunidad de estudiantes campesinos, pues al contar con un transporte que les permitiera realizar sus prácticas de acercamiento con otras escuelas, representaba una manera de vincularse con diversas experiencias formativas al conocer la vida de sus compañeros en otros estados y la geografía de otras regiones. El camión escolar también ayudaría en las prácticas de labor social que los alumnos y maestros realizaban durante la formación en la Regional Campesina, pues como recordamos entre las primeras peticiones del transporte, el 5 de abril de 1935, el trabajo de extensión social figuró como una demanda de la enseñanza de estos planteles.

Un año después, el 16 de abril de 1936, los alumnos del grado Normal enviaron al profesor Villarreal un plan de investigación y estudio a realizar en las próximas giras a las escuelas de Tenería, México y Roque, Guanajuato. La labor que realizarían consistía en convivir en las actividades cotidianas de los planteles según el grado que les correspondiera: asistencia a clases, participación en las labores agrícolas e industriales, desarrollo de un programa cultural y deportivo para cada plantel. El material indispensable para asistir sería:

\section{PRESUPUESTO:}

1. Alimentación

2. Transporte

3. Diez pesos a cada uno

4. Dos cámaras fotográficas con suficientes rollos

5. Géneros para dos uniformes de hombres; $110 \mathrm{~m}$ de color plomo y $110 \mathrm{~m}$ de color crema

6. $72 \mathrm{~m}$ de género para las señoritas; $36 \mathrm{~m}$ azul claro y 36 color blanco. ${ }^{18}$

Así, era necesario contemplar dicho material dentro del presupuesto demandado por los estudiantes normalistas, pues este tipo de prácticas requerían considerar las condiciones materiales de cada plantel y una preparación previa por parte de éstos. El viaje que los alumnos realizarían, en un primer momento, contempló la idea de visitar la escuela de La Huerta, Michoacán; en palabras de su profesor Albino Reyes, los alumnos que desearan visitar la Regional de Michoacán serían atendidos con gusto. El pago por raciones de alimentación

\footnotetext{
${ }^{18}$ AGN, SEP, DEANR, Sección Guerrero, Caja 33280, Referencia x/097.21(x-5-B)(727.1)/1, exp. 1, leg. 1, foja 12, Plan en investigación y estudio que se propone realizar el grado Normal, durante su próxima jira por las Escuelas de Tenería, Méx. y Roque, Gto., Ayotzinapa, Gro., 16 de abril de 1936.
} 
para el plantel era de \$0.50 centavos diarios que serían entregados a la Cooperativa de La Huerta que además, agregaba, contaba con camas suficientes para el número de alumnos que deseaban asistir, no así con el equipo de dormitorio que sólo alcanzaba para los de casa. ${ }^{19}$

Los primeros días de 1936 fueron convulsivos para la Escuela Regional Campesina de Ayotzinapa que atravesó una serie de conflictos internos y externos que iniciaron con el incidente del camión escolar, seguido por una pelea de alumnos contra jóvenes vecinos de Tixtla, el 20 de octubre de 1935, y varios ataques de elementos "clericales" de la región. El 21 de octubre de 1935, un acta del Consejo Consultivo de Maestros expulsó a 14 estudiantes de Ayotzinapa con motivo de una pelea con jóvenes de Tixtla. Sin permiso de los profesores, varios alumnos campesinos salieron de la escuela para presenciar la quema de toritos en el barrio de San Lucas, Tixtla, y cuando regresaban a la escuela una supuesta pandilla de jóvenes tixtlecos los atacó, resultando heridos los estudiantes Rubén Cuenca y Constantino Ramírez. Para terminar con la trifulca fue necesaria la intervención del Ejército y el Ministerio Público del lugar. Un mes después, ataques clericales se dirigieron en contra de los estudiantes cuando el 4 de noviembre de 1935 fueron interceptados por vecinos de la ciudad que exigían se les dijera si había Dios o no. La situación llevaría a los alumnos de Ayotzinapa a emplazar a huelga el 15 de abril de 1936, por lo que la presencia del jefe del Departamento de Enseñanza Agrícola y Normal Rural, Julián Villarreal, era necesaria.

La visita la realizó el 24 de abril y como resultado de ésta envió un informe al Secretario de Educación Pública explicándole que el funcionamiento de la institución era adecuado, pues "los maestros están trabajando con entusiasmo y los alumnos trabajan también con mucha dedicación y hay un gran espíritu de servicio y de fuerte cooperación con el Director" 20 Además, agregaba que entre las observaciones hechas a la Regional, los dos problemas principales del plantel eran la disputa por las tierras con los solicitantes de ejido de los terrenos de la escuela y las tensas relaciones con algunos "elementos fanáticos de Tixtla".

Al parecer, Villarreal sostuvo un encuentro con los estudiantes de quienes escuchó sus demandas, pues gracias a un telegrama, posterior a la fecha del 24 de abril de 1936, enviado por el director interino, Enrique Aguilar, el 6 de mayo, sabemos que el jefe del Departamento ofreció otro camión que realizara los viajes de estudio: "63.- Virtud camión Escuela llegó malas condiciones y necesitase acarreo materiales construcción, permitome recordarle ofre-

${ }^{19}$ El uso de camas no era una práctica muy difundida pero sí deseada, pues para 1949 Moisés de la Peña, en su libro Guerrero Económico narró "además de gran parte de la población indígena, aún hay importantes sectores de población mestiza en que los niños, por los menos, duermen en el suelo; pero ya el hecho de que al campesino le dé pena confesarlo, está próximo a remediar tan injustificada deficiencia, ya que nadie hay que sea tan incapaz como para no poder recoger un puñado de varas, atarlas y ponerlas sobre cuatro pequeños arcones con un cuadrilátero de delgados marcos de madera cortada a machete. Seguramente hay en Guerrero mucho más de 100,000 personas que duermen en el suelo y que forman parte de las que manifiestan dormir en cama" (Peña de la, 1949: 342).

${ }^{20}$ AGN, SEP, DEANR, Sección Guerrero, Caja 33282, Referencia x/166.2(x-5-B)(727.1), exp. 1, leg. 1, foja 3,4, Carta del Jefe del DEANR, Luis Villarreal al C. Secretario de Educación Pública, México, D. F., 24 de abril de 1936. 
cimiento en enviarnos otro camión verificar viaje Estudio". ${ }^{21}$ El 7 de mayo, el director, Aguilar, defendió la posición de que la escuela contara con dos camiones, uno de carga y otro para prácticas escolares; con respecto a la solicitud de viaje hecha por los estudiantes (suponemos la de abril a Tenería y Roque), escribió que le era imposible "controlar por más tiempo la impaciencia del Grado Normal” y al explicar la necesidad del camión señaló:

El plan de construcciones va por muy buen camino, solamente que juzgo necesario que el camión de la Escuela no nos acompañe en la jira, para que haga el acarreo de todo el material que hemos adquirido.

No quiero perder el ascendiente que hemos logrado; de no llevarse a acabo la jira de estudio, perderíamos gran parte del terreno ganado. ${ }^{22}$

Si bien la necesidad de un camión escolar propio para acarrear el material de construcción quedaba clara en su misiva, el segundo párrafo resulta confuso al referir que se perdería "gran parte del terreno ganado", es probable que esto último se deba a la confianza de los estudiantes en las autoridades escolares después de los acontecimientos de octubre de 1935 y como respuesta al emplazamiento a huelga en abril de 1936; motivada por el enojo de los estudiantes ante los constantes ataques de elementos clericales y la expulsión de sus compañeros por la pelea con jóvenes de Tixtla.

La petición de un segundo camión escolar hecha por Aguilar dice mucho sobre el significado de los acontecimientos de la volcadura y la fiesta, y sobre la presencia del visitador Villarreal en la Regional, pues dentro de los argumentos utilizados para convencer sobre lo necesario que resultaba un nuevo transporte, se contemplaba no cometer los errores pasados y, solicitar así, dos camiones que cumplieran finalidades distintas para la escuela.

La necesidad de destinar a alguien que manejara de la Ciudad de México a Tixtla reflejó nuevamente la preocupación por la destreza del chofer que conduciría por tramos del camino Tixtla-Chilpancingo y la carretera México-Acapulco. Recordemos que en octubre del año anterior, esto representó un problema, pues cuando el enviado de la SEP regresó al Distrito Federal y dejó a cargo de la Regional el camión marca "Reo", la inquietud por la preparación del maestro de taller Gilberto Martínez se hizo evidente al señalar que éste cada vez adquiría mayores conocimientos de manejo. El director, Aguilar, recordaba al jefe del DEARN la "promesa" hecha a sus muchachos. Los ánimos dentro de la Regional no parecían estar en calma.

${ }^{21}$ AGN, SEP, DEANR, Sección Guerrero, Caja 33280, Referencia x/097.21(x-5-B)(727.1)/1, exp. 1, leg. 1, foja 10, Telegrama de Enrique Aguilar al Profesor, Luis Villarreal, Ayotzinapa, Gro., 6 de mayo de 1936.

22 AGN, SEP, DEANR, Sección Guerrero, Caja 33280, Referencia x/097.21(x-5-B)(727.1)/1, exp. 1, leg. 1, foja 10, Carta de Enrique Aguilar al Profesor, Luis Villarreal, Ayotzinapa, Gro., 7 de mayo de 1936. 
El portador de la presente, señor Alvaro Ferrer, está bien dispuesto a traer el camión que ustedes nos proporcionaran; ojalá y que lo tuviéramos a más tardar el domingo por la mañana.

Que mis letras le recuerden la promesa que con tanto entusiasmo les hizo a mis muchachos y no se le olvide que estoy poniendo todo mi entusiasmo en la comisión que usted me ha encomendado. ${ }^{23}$

La carta del director, Aguilar, al tiempo de recordarle a Villarreal las promesas hechas a los estudiantes, presionaba para que esta demanda se cumpliera y no quedara en el olvido.

El 11 de mayo de 1936, mediante el acuerdo \#5546, el Departamento de Enseñanza Agrícola giró una orden al jefe del Departamento Administrativo para que se enviara un camión a más tardar el día 13 con el fin de que los estudiantes de la Normal pudieran realizar una visita a la Ciudad de México y a las Regionales Campesinas cercanas.

Entre las demandas que los alumnos expresaron estaba contar con un camión propio para sus viajes estudiantiles, quizá porque la experiencia de la volcadura había enseñado que era prioritario hacer la distinción entre un camión de carga y uno para viajes escolares. Los viajes escolares y un transporte destinado para tal fin fueron peticiones de los jóvenes de Ayotzinapa, que los vincularon con los autogobiernos escolares de Salaices, Chihuahua y el Mexe, Hidalgo, quienes al expresar su solidaridad con los de Guerrero manifestaron su deseo de realizar uno o dos viajes anuales de visita a otros plantes campesinos.

La carta que el gobierno escolar de Salaices envió al jefe del DEANR como respuesta a la circular núm. 1 enviada por los estudiantes de Guerrero refrendó el apoyo solicitado por los estudiantes de Ayotzinapa en el sentido de argumentar a favor de la necesidad de las prácticas de viaje, ya que:

con el fin de que ese Departamento autorice uno o dos viajes anuales a los alumnos del Grado Profesional de las Escuela Regionales Campesinas para que visiten otras Escuelas hermanas, con el fin de que los futuros Maestros se den exacta cuenta de los problemas que existen en otras regiones del país, así como que adquieran una mayor experiencia y reales conocimientos a fin de que llegado el tiempo en que tengamos que luchar por resolver tales problemas en beneficio de nuestras clases explotadas contemos con conocimientos prácticos para llevarlos a una pronta y eficaz resolución. [...] y ya que es el sentir de todos los estudiantes de las Regionales Campesinas y que sabemos claramente que a mayor preparación mayor rendimiento, y mientras nuestros Maestros Rurales no cuenten con esa preparación práctica y tengan una amplia visión de la realidad los resultados no serán los deseados.

${ }^{23}$ AGN, SEP, DEANR, Sección Guerrero, Caja 33280, Referencia x/097.21(x-5-B)(727.1)/1, exp. 1, leg. 1, foja 10, Carta de Enrique Aguilar al Profesor, Luis Villarreal, Ayotzinapa, Gro., 7 de mayo de 1936. 
Por lo antes expuesto creemos que nuestra petición no es injusta, ni tampoco perseguimos se nos proporcione un exparcimiento [sic.] a costa del erario público pues que el referido viaje será de estudio, un estudio en el que se obtendrán innumerables ventajas que en el aula no se obtiene. ${ }^{24}$

Así, cuando los alumnos solicitaron un camión escolar para sus viajes argumentaron la importancia de conocer por experiencia propia la vida de otras escuelas hermanas, aludiendo a la enseñanza práctica como parte del método pedagógico de este tipo de planteles. Los viajes no serían de recreación sino de trabajo. Aunque, también propiciaban un ambiente festivo entre los estudiantes. La respuesta de Villarreal fue clara y destacó que si bien el Departamento "simpatiza" con tales prácticas por considerarlas de gran utilidad, en ocasiones no se podía acceder a ellos por "causas económicas" y, concluía diciendo "en el caso de ustedes les indicamos se sirvan decirnos concretamente que es lo que desean para ver si es posible acceder a su solicitud" 25

Desde junio de 1935, la Federación de Estudiantes Campesinos Socialistas de México $(\text { FECSM })^{26}$ fue un factor que probablemente propició y dio cohesión al encuentro entre las distintas normales del país. El discurso de la Federación, similar al del Partido Comunista, pugnaba por el cumplimiento del plan sexenal de volver a todas las normales y centrales agrícolas, regionales campesinas; además de pedir mayor participación de los alumnos en el gobierno escolar, la depuración de maestros, agrónomos y normalistas "faltos de responsabilidad e ideología revolucionaria" y la creación de un Instituto de Educación Superior para la mayoría de sus maestros que se habían formado, principalmente, en normales urbanas (Civera, 2011: 88).

La respuesta de los estudiantes de Salaices al DEANR nos permite ver que los viajes fueron importantes para la formación y el reconocimiento entre escuela hermanas, por lo que Salaices pidió la autorización de dos viajes de estudio "a las Escuelas hermanas "Ricardo

${ }^{24}$ ACN, SEP, DEANR, Sección Guerrero, Caja 33280, Referencia x/097.21(x-5-B)(727.1)/1, exp. 1, leg. 1, foja 13, Carta del Gobierno Escolar de Salaices, Chihuahua al jefe del DEANR, Salaices, Chih., 23 de mayo de 1936.

${ }^{25}$ AGN, SEP, DEANR, Sección Guerrero, Caja 33280, Referencia x/097.21(x-5-B)(727.1)/1, exp. 1, leg. 1, foja 15, Carta del jefe del DEANR al Gobierno Escolar de Salaices, México, D.F., 11 de junio de 1936

${ }^{26}$ La Federación de Estudiantes Campesinos Socialistas de México nació a partir de la iniciativa de la sociedad de alumnos de la Central Agrícola de Tamatán, Tamaulipas, "Alma Campesina. A la par de identificarse como "partidarios de la escuela socialista", los alumnos lanzaron una convocatoria para organizarse en una sola federación que agrupara a los estudiantes de las distintas Centrales Agrícolas, Regionales Campesinas y Normales Rurales, esto como respuesta al interés del gobierno federal por organizar a la sociedad por ocupaciones (Ortiz, 2012: 115). ACN, SEP, DEANR, Sección Guerrero, Caja 33269, Referencia X/200 (04)(X-5)728.1/-1, exp. s/n, foja 67, Órgano de la Federación de Estudiantes Campesinos Socialistas de México, Oaxtepec, Mor., I de noviembre de 1935. Autores como Alicia Civera y Sergio Ortiz Briano hablan del surgimiento de la FECSM dentro de un contexto de organización sindical (Civera, 2013; Ortiz, 2012). 
Flores Magón" y "Santa Lucia Dgo". 27 Al igual que Chihuahua, El Mexe, Hidalgo, apoyó la petición de los de Ayotzinapa en su carta del 4 de julio enviada por su director que en sesión con el Consejo de alumnos y maestros decidieron reivindicar la demanda de los viajes escolares.

Para el 1 de junio de 1936, el viaje a la Escuela de Tenería se realizó con la participación de 38 estudiantes del grado Normal, tal como constató la carta del director de Ayotzinapa, Antonio Aguilar, quien pidió que se cubriera la cantidad de 190.00 pesos autorizados por la Secretaría para realizar el viaje "en virtud de que la referida cantidad la dio en carácter de préstamo el personal de esta Escuela". ${ }^{28}$ El importe total de los gastos que solicitó Aguilar fue cubierto por el DEANR como pago por concepto de cinco becas a estudiantes y, a su vez, Villarreal ordenó al jefe del Departamento Administrativo se tramitara el pago por un total de 200 pesos. Llama la atención que en la cantidad atribuida al pago solicitado hubiera un excedente de 10 pesos, una práctica poco común por parte del jefe del Departamento.

\section{Las deudas del plantel, un cuestionamiento al gobierno federal}

Si bien el camión de prácticas representó para los estudiantes la posibilidad de conocer otras escuelas "hermanas" y así construir una comunidad de estudiantes campesinos, la falta de recursos que se tradujo en deudas contraídas por el plantel con comerciantes guerrerenses significó un problema para la Regional que los distanció aún más de la vecina ciudad de Tixtla.

El 29 de mayo de 1937 el comerciante Julio Calva, residente en Chilpancingo, escribió una carta al secretario de Educación Pública donde expuso los motivos que lo llevaron a inconformarse contra la Regional de Ayotzinapa, se trataba de la deuda contraída por el plantel por concepto de gasolina ocupada en "varias actividades de la mensionada [sic] escuela". La escuela le compraba el combustible desde agosto de 1935 hasta febrero de 1937. El trabajador, como se nombró ante el secretario de Educación para exigir el pago de la deuda y destacar que era parte de la clase a la que defendía el gobierno de la República, se mostró indignado, pues no concebía posible que una escuela del gobierno federal no cubriera sus compromisos con el comercio que había ayudado en la construcción del edificio escolar:

\footnotetext{
${ }^{27}$ AGN, SEP, DEANR, Sección Guerrero, Caja 33280, Referencia x/097.21(x-5-B)(727.1)/1, exp. 1, leg. 1, foja 26, Carta del Gobierno Escolar de Salaices, Chihuahua al jefe del DEANR, Salaices, Chih., 10 de septiembre de 1936.

${ }^{28}$ AGN, SEP, DEANR, Sección Guerrero, Caja 33280, Referencia x/097.21(x-5-B)(727.1)/1, exp. 1, leg. 1, foja 17, Carta del director Enrique Aguilar G. al jefe del DEANR, Ayotzinapa, Gro., 1 de junio de 1936.
} 
Jamás creí que un plantel de esta índole no cubriera sus compromisos con el comercio, ya que se trata de una dependencia de la Secretaría más importante de nuestro Cobierno, y que por el papel que desempeña, debe ser toda moralidad, y sobre todo cuando se nota la voluntad de mi parte para proporcionar lo que fue necesario y de urgencia para dicho plantel, ya que de no haberlo hecho se hubieran suspendido las obras materiales que se hacían en la Escuela de Ayotzinapa, pues los camiones transportaron los materiales para dichas construcciones...29

La cantidad adeudada era de 569.48 pesos, que en palabras de Julio Calva, el director, Hipólito Cárdenas, no podía liquidar debido a que la SEP no autorizaba el pago, "[...] no obstante que en uno de los comprobantes que se me extendieron indican que una parte de esa Gasolina fue para ministrarla a varios camiones de la Secretaría de Educación Pública con motivo de una Escursión [sic.] que la misma Secretaría mandó..." 30

Una segunda carta llegó el 31 de mayo de 1937 procedente de Tixtla escrita por el dueño de la tienda de abarrotes "LA BUENA FE", Procopio González, comerciante y originario de la ciudad. En ella solicitaba, de igual forma que el comerciante de Chilpancingo, el pago de la deuda contraída desde mayo a diciembre de 1936, durante la dirección de Enrique Aguilar, por concepto de combustible utilizado en la planta de luz eléctrica del plantel. La cantidad a pagar era 207.10 pesos de la que no había sido cubierta ni "un solo centavo", pese al significativo monto de la deuda, el comerciante se mostraba más benévolo con la Regional:

30.- Que por ser amigo de la Escuela, se ha esperado hasta que al Director Aguilar le hubieran autorizado el pago según gestiones que él estuvo haciendo para ello.

40.- Que al haberse hecho el cambio de Director hace algunos días en dicha escuela y haberse presentado con tal motivo el Prof. Hipólito Cárdenas; se presentó ante él para hacerle presente la deuda que la escuela tiene pendiente, y

50.- Que siendo un comerciante en pequeño que paga sus mercancías al contado, cree conveniente suplicarle a usted se le gire la orden de pago al citado Prof. Cárdenas (que también ha estado gestionando el mismo asunto) para que le cubra la cuenta que la escuela reconoce.

Esperando una justa y favorable resolución a mi fundada petición, me es grato anticiparle las más repetidas gracias. ${ }^{31}$

\footnotetext{
${ }^{29}$ ACN, SEP, DEANR, Sección Guerrero, Caja 33266, Referencia x/122.2(x-5-B)(727.1), exp. 1, leg. 1, foja 9, Carta del comerciante Julio Calva C. al C. secretario de Educación Pública, Chilpancingo, Gro., 29 de mayo de 1937.

${ }^{30}$ AGN, SEP, DEANR, Sección Guerrero, Caja 33266, Referencia x/122.2(x-5-B)(727.1), exp. 1, leg. 1, foja 9, Carta del comerciante Julio Calva C. al C. secretario de Educación Pública, Chilpancingo, Gro., 29 de mayo de 1937.

${ }^{31}$ ACN, SEP, DEANR, Sección Guerrero, Caja 33266, Referencia x/122.2(x-5-B)(727.1), exp. 1, leg. 1, foja 30, Carta del comerciante Procopio González al C. jefe del Departamento de Enseñanza Agrícola y Normal Rural, Tixtla, Gro., 31 de mayo de 1937.
} 
En el problema de las deudas contraídas por el plantel escolar, la relación con el comercio de Tixtla podía representar un conflicto más grave si recordamos la tensa relación que la institución campesina tuvo con la vecina ciudad guerrerense debido a la disputa de tierras y el choque ideológico entre elementos religiosos y la educación socialista. Por su parte, la Escuela, desde un principio apoyó la solicitud de los comerciantes, pues como el director Cárdenas observó, el pago era necesario "a fin de dejar a esta Escuela en condiciones de seguir siendo atendida por el comercio, ya que es indispensable recurrir en muchos casos al crédito de que la Institución ha disfrutado". 32

El segundo reclamo que Julio Calva hizo al secretario de Educación en julio de 1937 fue acompañado, 15 días después, del apoyo de la Confederación de Cámaras Nacionales de Comercio e Industria que en una misiva pidió al Secretario de Educación se ordenara el pago de 569.48 pesos por los servicios de gasolina y lubricantes dados a la escuela. La deuda estuvo pendiente desde la administración del director, Enrique Aguilar, cuando la construcción del edificio escolar requirió de mayor transporte de material, por lo que la gasolina no sólo había servido para la excursión a Acapulco hecha por alumnos que asistieron también al Congreso en Tenería. El director Cárdenas manifestó no poder resolver el problema ya que no existía una orden por parte del Departamento que indicara de qué partida se podía "disponer para los pagos aludidos, pues mientras no haya orden los adeudos permanecerán insolutos". 33 Para la fecha en que Cárdenas envió el informe solicitado por el Departamento, la deuda por gasolina ya era mayor, pues el antiguo camión marca "Reo" había sido reemplazado por el "International". Las gestiones por el dinero duraron de mayo a octubre de 1937 y por orden directa del secretario, Gonzalo Vázquez Vela, se gestionó el pago de 500 pesos, considerando exclusivamente la cantidad que se le prometió al señor Julio Calva. Para el 5 de noviembre el trabajador de la Huasteca Petroleum Company aún no contaba con su pago debido a que su orden se encontraba en gestiones; no obstante, de no salir a tiempo, el señor Calva tendría que hacer nuevos trámites por estar cerca el fin de año. El conflicto se resolvió el 13 de abril de 1938 con el pago de 700 y 500 pesos para el señor Julio Calva y el resto para el tixtleco Procopio González.

\footnotetext{
32 AGN, SEP, DEANR, Sección Guerrero, Caja 33266, Referencia x/122.2(x-5-B)(727.1), exp. 1, leg. 1, foja 1, Carta de Hipólito Cárdenas al C. jefe del Departamento de Enseñanza Agrícola y Normal Rural, Ayotzinapa, Gro., I de junio de 1937.

${ }^{33}$ AGN, SEP, DEANR, Sección Guerrero, Caja 33266, Referencia x/122.2(x-5-B)(727.1), exp. 1, leg. 1, foja 13, Carta de Hipólito Cárdenas al C. jefe del Departamento de Enseñanza Agrícola y Normal Rural, Ayotzinapa, Gro., 15 de septiembre de 1937.
} 


\section{Conclusión}

La historia de la tecnología en México contempla no sólo el uso y consumo de objetos o artefactos sino que, además, hace énfasis en señalar que parte de estos estudios comprende también los discursos, valores e ideologías en los que están inmersos los objetos (Tinajero y Freeman, 2013). El desafortunado incidente de la volcadura del camión escolar permite observar un proceso, el de la introducción de este tipo de tecnologías a las escuelas campesinas y a regiones del estado de Guerrero que no contaban con un mayor número de automóviles privados. Para 1935 casi la mitad del total de camiones en el país pertenecían al sector público, en este sentido, resulta interesante el cuestionamiento que Julio Calva hizo a la Secretaría de Educación por el adeudo de gasolina. El comerciante no concebía posible que una escuela representante del gobierno federal y símbolo de la modernidad dejara de cumplir con sus compromisos de comercio en la región.

La Regional Campesina de Ayotzinapa, como Alicia Civera (2013) sugiere, representó una "opción de vida" para el estudiante campesino que fue de los primeros en contar con camiones escolares nuevos para el plantel, basta recordar el señalamiento del Rubén Castillo Penado sobre el escudo que llevaba el camión en las portezuelas y que lo identificaba como propiedad de la Secretaría de Educación y de la escuela para saber que éste fue importante para el director.

No obstante, como demuestra el accidente, las carencias materiales trajeron consigo otro tipo de problemas y juicios para la institución tales como el conflicto con el Departamento de Tráfico del estado, en donde los alumnos fueron nombrados "macheteros" debido al mal uso que hicieron del transporte de carga. Su doble uso visibilizó la necesidad existente de aprovechar al máximo los recursos con los que contaba el plantel, al mismo tiempo que representó un fuerte cuestionamiento para las autoridades escolares y federales que permitieron se transportara a sus alumnos con tan fatal desenlace. De tal forma que, cuando los estudiantes y algunas organizaciones sociales protestaron por la expulsión de 14 de ellos como consecuencia de la pelea con jóvenes de Tixtla el 21 de octubre de 1935, los argumentos de ambas organizaciones iban dirigidos a la responsabilidad de las autoridades y maestros por la seguridad y moral de sus hijos o vecinos. Cuando los estudiantes emplazaron a huelga el 16 de abril de 1936, el accidente del camión escolar y los agravios cometidos contra ellos por grupos fanáticos los posicionaron de una manera distinta en la negociación con las autoridades de la Secretaría de Educación Pública que para dirimir el conflicto enviaron al jefe del DEANR, quien prometió otro camión para prácticas escolares.

Para 1935 se observa un interés por parte de los estudiantes en visitar "escuelas hermanas" para aprender de la convivencia de la vida de otros planteles. Este punto resulta particularmente interesante porque agrega un factor más a los estudios sobre las prácticas y 
excursiones escolares y que indaga en el interés de los alumnos por formar lazos de comunidad estudiantil con otras regionales campesinas. Los estudios que han centrado su atención en la formación de organizaciones de normalistas rurales (Ortiz, 2012) relatan el surgimiento de la Federación de Estudiantes Campesinos Socialistas de México (FECSM) como un elemento que aglutinó la organización de estudiantes en el país.

La prensa fue un mecanismo que ayudó a dicha cohesión; sin embargo, el uso de nuevas tecnologías que para 1930 comenzaban a ser más frecuentes nos permite pensar en un elemento material que ayudó a volver tangible el acercamiento entre estudiantes. Comunidades de futuros maestros rurales y técnicos agrícolas se apropiaron de estas nuevas máquinas.

A manera de hipótesis, se sugiere pensar en el surgimiento de estas nuevas tecnologías como un factor que propició la apropiación de la demanda de los viajes escolares por los estudiantes al volverlos más realizables en términos de costos económicos. Aunque, como vimos, los costos también se tradujeron en deudas con una parte del comercio guerrerense, que dada la difícil situación por la que atravesaba el plantel con la vecina ciudad de Tixtla, pusieron en riesgo la estabilidad de la escuela, la confianza en el gobierno federal y las relaciones entre la población vecina y los estudiantes.

\section{Fuentes}

Arata, Nicolás (2014), "Formar lectores, sensibilizar espíritus. La organización de la Biblioteca Nacional de Maestros (1870-1906)", en Pablo Pineau (coord.), Escolarizar lo sensible. Estudios sobre estética escolar (1870-1945), Editorial Teseo, Buenos Aires.

Barbieri, Patricia (2014), "La arquitectura escolar. Una mirada desde la estética de la vida cotidiana", en Pablo Pineau (coord.), Escolarizar lo sensible. Estudios sobre estética escolar (1870-1945), Editorial Teseo, Buenos Aires.

Benítez, José (1928), Guía Histórica y Descriptiva de la Carretera México-Acapulco, Editorial "Cultura", México.

Bustamante Álvarez, Tomás (1987), Historia de la cuestión agraria mexicana. Estado de Guerrero 1867-1940, Gobierno del Estado de Guerrero, Universidad Autónoma de Guerrero, Centro de Estudios Históricos del Agrarismo en México, México, pp. 337-354.

(1998), Historia General de Guerrero. La Reconstrucción, INAH-Gobierno del Estado de GuerreroJGH Editores, México.

Calderón Mólgora, Marco (2013), "La ciudad en el campo. Construcción del Estado y cambio cultural en México: 1920-1940", en L. Lionetti, A. Civera y F. Obino Correa (eds.), Sujetos, comunidades rurales y culturas escolares, Ediciones Prohistoria, El Colegio Mexiquense, El Colegio de Michoacán, Rosario, Argentina y Zinacantepec, México.

Civera Cerecedo, Alicia (1997), Entres surcos y letras. Educación para campesinos en los años treinta, El Colegio Mexiquense, A. C., Zinacantepec, México.

(2004), "Pedagogía Alternativa y revolución: la formación de maestros normalistas rurales en México, 1922-1945", El Colegio Mexiquense, A. C., (Documentos de Investigación 93), Zinacantepec, México, documento pdf disponible en: <http://www2.cmq.edu.mx/libreria/index.php/publi- 
caciones/distribucion-gratuita/documentos-de-investigacion / item/188-pedagogia-alternativa-y-revolucion-la-formacion-de-maestros> (consulta: 30/09/2016).

(2011), "iPor qué somos estudiantes de segunda!: la organización de los estudiantes campesinos en México, 1932-1941”, en González Marín, S. y Sánchez Sáenz, A., 154 años de movimientos estudiantiles en Iberoamérica, UNAM, México, pp. 79-104.

(2013), La escuela como opción de vida. La formación de maestros normalistas rurales en México 1921-1945, 2a ed., El Colegio Mexiquense, A. C.-Fondo Editorial Estado de México/Gobierno del Estado de México, Toluca, México.

Darnton, Robert (1987), La gran matanza de gatos y otros episodios en la historia de la cultura francesa, FCE, México.

Fulwider, Benjamin (2009), Driving the nation: road transportation and the potsrevolutionary mexican state, 1925-1960, tesis doctoral en Historia, Faculty of the Graduate School of Arts and Sciences, Georgetown University.

Garay Molina, Claudia (2010), "En busca de un libro de texto: el caso de Simiente", en Renato González Mello y Deborah Dorotinsky Alperstein (coords.), Encauzar la mirada. Arquitectura, pedagogía e imágenes en México. 1920-1950, unAM, México, pp. 109-141.

Guajardo Guillermo y Paolo Riguzzi (2013), "Railroad Culture and Mobility in Tentieth-Century Mexico", en A. Tinajero y B. Freeman (eds.), Technology and culture in twentieth-century Mexico. Univesity of Alabama Press, Tuscaloosa, Alabama, pp. 233-248.

INEGI (Instituto Nacional de Geografía y Estadística) (1998), Tixtla, tierra fértil de hombres y frutos, INEGI, México.

Jacobs, Ian (1990), La revolución mexicana en Guerrero: una revuelta de los rancheros, Era, México.

Lawn Martin y Ian Grosvenor (eds.) (2005), Materialities of Schooling. Design-Technology-ObjectsRoutines, Cambridge University Press, Reino Unido.

Martínez Moctezuma, Lucía (2002), "Educar fuera del aula: los paseos escolares durante el porfiriato", Revista Mexicana de Investigación Educativa, vol. 7, núm. 15, pp. 279-302.

(2009), "Cultura escrita en las excursiones normalistas del estado de Morelos", Revista Mexicana de Investigación Educativa, vol. 9, pp. 1-19.

Ortega Ibarra, Carlos y Saldaña Juan (2013), "Primeros reglamentos técnicos en la arquitectura escolar mexicana (1880-1920)", Quipu, vol. 15, núm. 1, enero-abril, pp. 49-70.

Ortiz Briano, Sergio (2012), Entre la nostalgia y la incertidumbre. Movimiento estudiantil en el normalismo rural mexicano, Universidad Autónoma de Zacatecas, México.

Palacios, Guillermo (1996), Los intelectuales posrevolucionarios y la construcción sociocultural del problema campesino en los años treinta, Centro de Investigación y Docencia Económicas, México.

(1999), La pluma y el arado: los intelectuales pedagogos y la construcción sociocultural del problema campesino en México: 1932-1934, El Colegio de México, México

Peña de la, Moisés (1949), Guerrero Económico, México, Gobierno del Estado de Guerrero.

Tinajero Araceli y Brian Freeman (2013), Technology and culture in twentieth-century Mexico, Univesity of Alabama Press, Tuscaloosa, Alabama.

Torres Hernández, Rosa María (1998), Influencia de la teoría pedagógica de John Dewey en el periodo presidencial de Plutarco Elías Calles y el Maximato. 1924-1934, tesis doctoral, UnAm,México.

Vaughan, Mary Kay (2000), La políica cultural en la revolución. Maestros, campesinos y escuelas en México 1930-1940, SEP-FCE, México.

Waters, Wendy (1999), "Re-mapping the nation: Road building as state formation in postRevolutionary Mexico, 1925-1940", tesis doctoral en Filosofía, Univerity or Arizona, Tempe, AZ. 
(2006), "Remapping Identities: Road Construction and Nation Building in Postrevolutionary México", en Mary K. Vaughan y Stephen Lewis (eds.), The Eagle and the virgin. Nation and Cultural

Revolution in México, 1920-1940, Duke University Press, Durham, NC, pp. 221-235. Archivos consultados

AGN Archivo General de la Nación

AHSEP Archivo Histórico de la Secretaría de Educación Pública

Karina Araceli Flores Cordero. Maestra en Ciencias con especialidad en Investigaciones Educativas por el Departamento de Investigaciones Educativas, Cinvestav. Licenciada en Historia por la Facultad de Filosofía y Letras de la Universidad Nacional Autónoma de Mexico. Líneas de investigación: educación y normalismo rural en el México posrevolucionario.

Recibido: 30 de marzo de 2017.

Aceptado: 8 de mayo de 2017. 